\title{
Orações adjetivas em redações: estratégias de estruturação textual e de organização da informação
}

\author{
Paulo Ricardo Soares Pereira ${ }^{1}$ \\ Maria Augusta Gonçalves de Macedo Reinaldo 2
}

Resumo: Este trabalho tem por objetivo analisar, através de uma pesquisa qualitativa, descritiva e documental, a recorrência de orações subordinadas adjetivas em redações de candidatos ao Exame Nacional no Ensino Médio (ENEM) submetidas à avaliação pelo portal UOL Educação. Após a coleta dos dados e da triagem dos conectivos e das orações adjetivas, levantamos algumas hipóteses de cunho didático, confrontando os dados com os fundamentos teóricos de Bagno (2011) e Castilho (2012). Em um diagnóstico geral do corpus analisado, no que se refere à recorrência no uso dos pronomes, identificamos: maior recorrência (predomínio) no uso do pronome relativo que; poucos/raros os casos de uso dos pronomes onde / em que / qual / quem (e suas variações); uso do pronome relativo cujo (e suas variações) inexistente. Em relação à recorrência no uso das orações adjetivas, temos: predomínio no uso das adjetivas restritivas; raros casos de adjetivas livres; utilização da oração adjetiva cortadora. Com base nos aspectos de referenciação, coesão e sequenciação, encontramos: problemas na utilização do pronome adequado.

Palavras-chave: Orações subordinadas adjetivas. Estratégias de relativização. Ensino de sintaxe.

\section{Subordinate relative clauses in essays: strategies of text formation and organization and organization of information}

\begin{abstract}
This work aims at analyzing, through a qualitative, documental and descriptive research, the recurrence of relative clauses in essays written by candidates for the National High School Examination (Exame Nacional do Ensino Médio - ENEM). Such essays are submitted to evaluation by the Education Website UOL. After data collection, the connectives and relative clauses are screened; and some hypotheses are raised, comparing the data collected with the theoretical foundations proposed by Bagno (2011) and Castilho (2012). In a general diagnostic of the analyzed corpus, concerning the use of the pronouns, we identified a predominance of the relative pronoun that; a few cases of use of the pronouns where / in which / which / who (and its variations); and the absence of the use of the relative pronoun whose (and its variations). Regarding the subordinate relative clauses, we observed a prevalence of the defining relative clauses; and a few cases of non-defining relative clauses. On the subject of referencing, cohesion and sequencing, we found out problems in the use of the appropriate pronoun.
\end{abstract}

Keywords: Relative clauses. Relativization strategies. Syntax Teaching.

\section{Introdução}

Quando observamos o contexto do ensino de Língua Portuguesa na Educação Básica brasileira, vemos que o método tradicional ainda é muito forte; não que ele seja de todo negativo, mas da forma como é aplicado dispõe a língua, no mínimo, como algo

\footnotetext{
${ }^{1}$ Graduando em Letras com habilitação em Língua e Literatura Portuguesa, pela Universidade Federal de Campina Grande (UFCG). E-mail: pauloricardo_sp_@hotmail.com

${ }^{2}$ Professora, Doutora da Unidade Acadêmica de Letras (UAL) da Universidade Federal de Campina Grande (UFCG), campus Campina Grande. E-mail: freinaldo@uol.com.br
} 
uniforme e norteada por regras e normas prescritas. No que diz respeito ao ensino da Sintaxe, professores e livros didáticos parecem entender que a mera classificação de termos e de orações é o que há de mais relevante para o aluno aprender. Não há trabalho maciço na função e nas aplicações destas estruturas linguísticas em contexto real de uso da língua. Nesse contexto de desarticulação entre metalinguagem e uso linguístico, é compreensível o ato de um aluno perguntar a si mesmo ou ao professor: Onde eu vou usar esse conteúdo?

Em se tratando de Sintaxe, as orações tradicionalmente conhecidas como subordinadas adjetivas correspondem ao que o viés gramatical funcionalista nomeia como subordinadas relativas, com foco nas estratégias de relativização, muito importantes e pertinentes para diversas aplicações e intenções discursivas na produção textual. Muitos estudos têm sido desenvolvidos a respeito desse assunto, sobretudo quanto à relevância do ensino dessas estratégias que, normalmente, contrariam a noção de relativização padrão da Gramática Tradicional.

Nesse sentido, este trabalho ${ }^{3}$ tem por objetivo geral analisar o comportamento das orações subordinadas adjetivas em redações de candidatos ao Exame Nacional do Ensino Médio (ENEM) ${ }^{4}$. Especificamente, identificaremos a recorrência de orações subordinadas adjetivas nas redações de candidatos ao Exame, e levantaremos hipóteses de ordem didática sobre o comportamento linguístico dos candidatos quanto ao emprego dessas orações em suas redações.

A competência aqui avaliada é a de número 04 (quatro), isto é, a de demonstrar conhecimento dos mecanismos linguísticos necessários para a construção da argumentação. Segundo as orientações para a redação do ENEM, contidas no Guia do Participante 2013, esta competência se propõe avaliar se o aluno sabe construir um texto

\footnotetext{
${ }^{3}$ Artigo construído no âmbito da disciplina Sintaxe Interacional, da Universidade Federal de Campina Grande (UFCG), campus Campina Grande. A produção desse artigo é fruto também, das discussões em conjunto com o discente Francinaldo de Souza Lima.

${ }^{4}$ Redações produzidas no ano de 2012 e 2013, extraídas do banco de redações do site UOL - Educação. Site no qual o estudante pode enviar sua redação para avaliação e encontra exemplos de textos (redações) avaliados por uma equipe especializada em correção de provas e redações de vestibular e ENEM. A banca responsável pela correção das redações segue os mesmos critérios de avaliação do Exame Nacional do Ensino Médio, a saber 05 (cinco) competências: Competência 1: Demonstrar domínio da modalidade escrita formal da Língua Portuguesa; Competência 2: Compreender a proposta de redação e aplicar conceitos das várias áreas de conhecimento para desenvolver o tema, dentro dos limites estruturais do texto dissertativo-argumentativo em prosa; Competência 3: Selecionar, relacionar, organizar e interpretar informações, fatos, opiniões e argumentos em defesa de um ponto de vista; Competência 4: Demonstrar conhecimento dos mecanismos linguísticos necessários para a construção da argumentação e Competência 5: Elaborar proposta de intervenção para o problema abordado, respeitando os direitos humanos. (BRASIL, 2013, p. 08)
} 
coeso utilizando corretamente os mecanismos de encadeamento textual disponíveis na Língua Portuguesa, tanto na estruturação dos parágrafos, como dos períodos e na referenciação textual (BRASIL, 2013). Seguem abaixo as recomendações do instituto organizador do Exame para os estudantes, sobre esta competência:

Procure utilizar as seguintes estratégias de coesão para se referir a elementos que já apareceram anteriormente no texto:

a) substituição de termos ou expressões por pronomes pessoais, possessivos e demonstrativos, advérbios que indicam localização, artigos;

b) substituição de termos ou expressões por sinônimos, antônimos, hipônimos, hiperônimos, expressões resumitivas ou expressões metafóricas;

c) substituição de substantivos, verbos, períodos ou fragmentos do texto por conectivos ou expressões que resumam e retomem o que já foi dito; e

d) elipse ou omissão de elementos que já tenham sido citados anteriormente ou sejam facilmente identificáveis.

Resumindo: na elaboração da redação, você deve, pois, evitar:

- frases fragmentadas que comprometam a estrutura lógicogramatical;

- sequência justaposta de ideias sem encaixamentos sintáticos, reproduzindo usos típicos da oralidade;

- frase com apenas oração subordinada, sem oração principal;

- emprego equivocado do conector (preposição, conjunção, pronome relativo, alguns advérbios e locuções adverbiais) que não estabeleça relação lógica entre dois trechos do texto e prejudique a compreensão da mensagem;

- emprego do pronome relativo sem a preposição, quando obrigatória; e

- repetição ou substituição inadequada de palavras sem se valer dos recursos oferecidos pela língua (pronome, advérbio, artigo, sinônimo). (BRASIL, op. cit., p. 20).

Este trabalho mostra-se relevante, pois, após análise dos dados, traz uma reflexão sobre a eficácia do método de ensino que, em termos gerais, é encontrado nas escolas do Brasil atualmente, além de nos fazer perceber com que frequência os alunos recorrem a estratégias não prestigiadas da língua, contrariando, muitas vezes, por assim dizer, a norma padrão.

A tradição de descrever apenas a estrutura presente na norma padrão por si só não é mais suficiente. É necessário levar os alunos a refletirem sobre a língua e sobre a língua em uso, o que contempla, obviamente, também, as orações subordinadas adjetivas, sobre as quais, discute Bagno (2011): 
A regra normativa de emprego dos pronomes relativos pertence ao que poderíamos chamar 'gramática invisível': um conjunto de regras prescritas pela tradição, mas que não fazem mais nenhum sentido para o processamento intuitivo da língua por parte dos falantes (...) Diante disso, o tratamento das sentenças adjetivas em sala de aula representa um grande desafio para a educação linguística. (BAGNO, 2011, p. 911)

Este trabalho está divido em 05 (cinco) partes, a saber: esta breve introdução seguida da metodologia da pesquisa; posteriormente, temos a fundamentação teórica e a análise dos dados, encerrando com as considerações finais.

\section{Metodologia da pesquisa}

Para alcançarmos tais objetivos, analisamos 20 (vinte) redações coletadas do portal UOL Educação ${ }^{5}$ que sugere mensalmente uma proposta de redação e propõe avaliação de produções textuais submetidas ao site nos termos do ENEM.

Feita a leitura de todo o material, separamos alguns textos que constituem um corpus representativo, sem nos preocuparmos com problemas de ordem puramente gramatical (ortografia, pontuação, concordância etc). Só então, iniciamos a seleção necessária para o estudo a que nos propomos, destacando os excertos que satisfaziam o objetivo desta pesquisa.

Após a coleta dos dados, seguimos os seguintes critérios de análise:

$\checkmark$ Recorrência dos conectivos (que, quando, quanto, cujo, onde) e forma empregada (função sintática, sequencial ou referencial);

$\checkmark$ Recorrência das orações subordinadas adjetivas segundo critério sintático (padrão, cortadora e copiadora) e semântico (explicativas, restritivas). Realizada a fase de coleta dos dados, segundo essa orientação, levantamos hipóteses quanto ao ensino das orações subordinadas adjetivas, tendo em vista os resultados mais relevantes encontrados nas produções textuais

\footnotetext{
${ }^{5}$ Links de acesso: (1) http://educacao.uol.com.br/bancoderedacoes/; (2) http://educacao.uol.com.br/bancoderedacoes/temas.jhtm
} 
analisadas. Dessa forma, este trabalho se apresenta como uma pesquisa qualitativa, descritiva de cunho documental.

\section{Fundamentação teórica}

Apresentamos, nesta seção, o que registram os compêndios gramaticais mais tradicionais (BECHARA, 2009; CUNHA; CINTRA, 2001) e os estudos linguísticos sobre a relativização (CASTILHO, 2012); (conceitos, estratégias e exemplos), além de uma breve discussão em torno das funções textuais-discursivas promovidas em torno do processo de relativização (DECAT, 2004).

\subsection{Quanto à relativização}

Sabemos que a Gramática Normativa e os estudos Linguísticos têm visões diferentes sobre a questão da relativização, em especial no que diz respeito às orações adjetivas/relativas. Tais discrepâncias teóricas serão discutidas mais profundamente a partir de agora.

Segundo a visão normativa, orações relativas são orações subordinadas a um núcleo substantivo, ou a um elemento equivalente a um substantivo na oração anterior - o antecedente - e são encabeçadas, quando desenvolvidas, por um pronome relativo, que retoma esse antecedente. São conhecidas, tradicionalmente, como orações subordinadas adjetivas. Via de regra, as gramáticas tradicionais não discutem os processos de construção relativa. Limitam-se a conceituar/definir as orações relativas e a apresentar sua classificação prototípica em restritivas e explicativas (BECHARA, 2009; CUNHA; CINTRA, 2001). Além disso, na definição que apresentam, esses manuais geralmente não utilizam uma abordagem unificada, confundindo, muitas vezes, critérios de naturezas distintas: ora sintáticos, ora semânticos e/ou pragmáticos, ora os três simultaneamente.

De acordo com Cunha e Cintra (2001, p. 586), “as ORAÇÕES SUBORDINADAS ADJETIVAS vêm normalmente introduzidas por um PRONOME RELATIVO, e exercem a função de ADJUNTO ADNOMINAL de um substantivo ou pronome antecedente" (destaques do autor). A seguir, exemplos apresentados pelos próprios autores: 
(1) Era uma cachopa um tanto atarracada, que usava meias palmilhadas e anéis de latão.

(2) Na petição de privilégio que então redigi chamei a atenção do governo para este resultado, verdadeiramente cristão (op. cit., p. 587)

$\mathrm{Na}$ ação de descrição da língua, é normal que as gramáticas apresentem não só conceitos, mas também a classificação das estruturas linguísticas. A respeito disso, quanto da classificação das orações subordinadas adjetivas, Cunha e Cintra afirmam:

Quanto ao sentido, as SUBORDINADAS ADJETIVAS classificamse em RESTRITIVAS e EXPLICATIVAS.

1. As RESTRITIVAS, como o nome indica, restringem, limitam, precisam a significação do substantivo (ou pronome) antecedente. São, por conseguinte, indispensáveis ao sentido da frase; e, como se ligam ao antecedente sem pausa, dele não se separam, na escrita, por vírgula.

2. As EXPLICATIVAS acrescentam ao antecedente uma qualidade acessória, isto é, esclarecem melhor a sua significação, à semelhança de um aposto. Mas, por isso mesmo, não são indispensáveis ao sentido essencial da frase. Na fala, separam-se do antecedente por uma pausa, indicada na escrita por vírgula. (CUNHA; CINTRA, 2001, p.588).

Vejamos, agora, o que diz a visão funcionalista sob o olhar de Castilho (2012). De início, é importante lembrar que a nomenclatura destas estruturas muda, sendo chamadas ainda de orações adjetivas, mas principalmente de orações relativas, recebendo esse nome pela função semântica e sintática que desenvolvem no sintagma nominal.

Sentenças complexas encaixadas: uma sentença está encaixada num constituinte de outra, gerando-se os seguintes tipos de dependência: (...) o encaixamento ocorreu no sintagma nominal, como em - $O$ aluno que falou era o melhor da classe - estabelecendo uma relação de adjunção a esse sintagma - estas são as adjetivas, ou relativas.

(CASTILHO, 2012, p. 339).

Segundo Castilho (2012), “As adjetivas ou relativas são sentenças encaixadas num sintagma nominal, em atuam como complementadores", logo, "o processo de relativização é, portanto, o relacionamento de dois sintagmas nominais correferenciais", no qual devem ser observados seus aspectos e propriedades sintáticos e semânticos.

Vejamos alguns exemplos dados pelo autor:

(3) [O aluno atento] passa de ano.

(4) [O aluno estudioso] passa de ano. 
(5) [O aluno atento que é estudioso] passa de ano.

Aluno atento e aluno estudioso são correferenciais, remetem ao mesmo indivíduo. (Castilho, 2012, p. 366).

Vimos, depois da explanação acerca das duas visões, que ambas apresentam as orações adjetivas como estruturas que giram em torno de pronomes relativos. Quanto a esta questão, também encontramos algumas divergências entre o que diz a tradição gramatical e o que diz a visão funcionalista. Vejamos, agora, algumas considerações a respeito deste tema, antes de partirmos para as relações textuais e discursivas das orações adjetivas. Tradicionalmente, os pronomes relativos, conforme Bechara (2009, p. 199), "[...] são os que normalmente se referem a um termo anterior chamado antecedente". Ele elenca os seguintes pronomes relativos: "qual, o qual (a qual, os quais, as quais), cujo (cuja, cujos, cujas), que, quanto (quanta, quantos, quantas), onde". Assim,

Em A cidade a que nos dirigimos ainda está longe, o relativo que reintroduz na oração subordinada adjetiva a que nos dirigimos o substantivo cidade, e vale por nos dirigimos à cidade, em que o núcleo verbal dirigimos requer um termo argumental marcado pelo índice preposicional $a$, preposição que, portanto, não deve faltar anteposta ao relativo, que funciona como complemento relativo do núcleo verbal nos dirigimos: A cidade a que nos dirigimos ainda está longe. (BECHARA, 2009, p. 466).

Se por um lado temos uma visão tradicional, por outro lado, numa visão mais ampla que já abarca os pronomes e suas relações nas orações adjetivas, Castilho (2012, p. 366) aponta "que as adjetivas são introduzidas por pronomes relativos, que integram uma classe fechada, a saber, que, qual, cujo, quanto, onde". Bagno (2011), em sua Gramática Pedagógica do Português Brasileiro comenta:

Os pronomes relativos, em seu emprego padronizado, estão em processo de extinção e coube à nossa geração presenciar esse desaparecimento. Tudo indica que, em breve eles vão se se juntar ao acervo de relíquias gramaticais que os falantes da língua vêm depositando ao longo dos séculos no arquivo morto da língua: - o índice de pessoa vós e seus possessivos; - a distinção entre mui e muito [...] (BAGNO, 2011, p. 917).

Em termos estruturais, os exemplares de orações relativas de que se ocupam os compêndios gramaticais correspondem ao modelo padrão. Estratégias de relativização é 
a denominação atribuída a um conjunto de três estruturas das quais duas são ignoradas pela Gramática Tradicional e somente uma - a padrão - é prescrita. Segundo abordagens linguísticas, são três os casos de relativização utilizados no português do Brasil: o caso da relativa padrão; o da relativa cortadora e o da relativa copiadora (CASTILHO, 2012).

$\mathrm{Na}$ adjetiva padrão, os pronomes relativos exibem as formas correspondentes ao caso que recebem de seu verbo:

(...) b) Perdi o livro que estava lendo. (caso acusativo, função de objeto direto) (...)

d) Não há uma área em São Paulo em que a polícia não entre. (caso ablativo, função de complemento oblíquo) (...) Na língua formal, que ainda conserva o valor pronominal dos relativos (...) (CASTILHO, 2012, p. 367).

Observemos que o pronome relativo que no exemplo (d) foi precedido pela preposição em. É esse o uso prescrito pelas gramáticas normativas para esse caso de relativização, visto que o verbo entrar rege a preposição em. As gramáticas normativas prescrevem como correta a existência de apenas uma estratégia de relativização: aquela em que a preposição aparece obrigatoriamente no contexto do sintagma. Por ser a estratégia de relativização considerada pelas gramáticas normativas como a que obedece à norma-padrão, no âmbito deste trabalho, será denominada de relativa padrão.

Além da chamada relativa padrão, os estudos linguísticos têm mostrado que aparecem no português falado por brasileiros em geral, outras duas estratégias de relativização: a relativa copiadora e a relativa cortadora.

Sentença adjetiva copiadora

Quando o pronome se despromoninaliza, reduzindo-se à condição de conjunção, ele perde a propriedade fórica, que será preenchida por um pronome pessoal preposicionado ou não: a.1) Não há uma área em São Paulo que a polícia não entre nela. (...)

Sentença adjetiva cortadora

a.2) Não há uma área em São Paulo que a polícia não entre (CASTILHO, 2012, p. 367).

Em (a.1), a relativa diverge do padrão porque o antecedente do pronome relativo é copiado na oração subordinada, por meio dos anafóricos nela, ao passo que, em (a.2), ocorre a supressão (corte) da preposição em, regida pela forma verbal entre. Essas relativas são denominadas, na literatura linguística, copiadora e cortadora, respectivamente. 
Essas estratégias são tratadas, pela maioria dos manuais de gramática tradicional, como meros desvios da forma canônica e, por isso, devem ser evitadas. Esses usos não são descritos nas gramáticas tradicionais e têm sido considerados pela escola como um erro, uma falta de conhecimento do sistema preposicional da língua prescrito como a norma-padrão. Entretanto, diversos estudos de orientação sociolinguística atestam que as relativas não-padrão são largamente empregadas por usuários da língua de diferentes níveis de escolaridade e em diferentes contextos comunicativos, inclusive alguns que envolvem maior formalidade. "Na língua falada, que é uma espécie de pronome relativo universal, que está ocupando os espaços dos outros.” (CASTILHO, 2012, p. 366).

\title{
3.2 Quanto às funções textuais-discursivas
}

A produção de um texto dissertativo-argumentativo decorre de uma atividade comunicativa e interativa, a qual pressupõe que seja apresentada uma opinião (ponto de vista) favorável - ou não - subjacente em justificativas que se caracterizam como argumentos. Configura-se, pois, de um processo de produção textual proposital e determinado pela mobilização de estratégias concretas e seleção dos instrumentos apropriados em função de um objetivo maior: constituir comunicação e produzir significação/sentido(s).

Nesse sentido, é necessário que os produtores de textos dominem uma série de estratégias de organização da informação e de estruturação textual.

\begin{abstract}
A necessidade de reforçar um ponto de vista, de dar realce, ênfase a um determinado aspecto, leva o produtor do texto a fazer uso de seqüências argumentativas, materializadas lingüisticamente através da estratégia do 'desgarramento' de orações ou de SNs. É uma maneira de alertar o leitor para uma informação, ou uma opinião, que ele, autor do texto, não quer que passe despercebido (DECAT, 2004, p. 87).
\end{abstract}

A utilização das orações relativas serve a essa função. Em outras palavras, a oração relativa é considerada como um dos recursos sintáticos para dar relevo, ênfase ao que é dito. Ao ocorrer, vem comprovar a sua força argumentativa. A retomada, a avaliação dessa informação - ao fazer uso das adjetivas/relativas - realiza-se, através de referência ou remissão textual, formando, no texto, estruturas referenciais coesivas. A formação dessas 
estruturas/cadeias coesivas na organização textual colaboram efetivamente para a construção do sentido textual.

É nesse sentido que Decat (2004, p.99) afirma "serem as orações apositivas também estratégias de focalização, de realce, de relevo, visando a uma maior argumentatividade" e mostra que estas estruturas têm ganhado espaço não só no Português Brasileiro, mas também no Europeu contribuindo para a riqueza dos recursos coesivos do texto.

(...) orações relativas apositivas,chamadas de adjetivas explicativas pela Gramática Tradicional, é mais uma das estratégias de focalização, juntamente com a clivagem, com a topicalização e outros. Há que se reconhecer, portanto, a produtividade cada vez maior dessa estratégia no português escrito, brasileiro ou europeu, evidenciando não uma 'falha' de organização do texto, como querem os prescritivistas, mas uma tendência da língua para a construção textual e uma estratégia importante para a organização das informações no texto, a qual se caracteriza como mais um recurso sintático para a atribuição de relevo a partes do enunciado (DECAT, 2004, p.99).

\section{Análise dos dados}

Nesta seção, nos dedicamos à análise de alguns excertos dos textos de alunos, que constituem o corpus desta pesquisa, nos quais se verificam variações das estruturas relativas utilizadas na redação. Foram analisados somente os aspectos estruturais das orações adjetivas, descartando-se problemas como ineficácia ortográfica e outros. Em um diagnóstico geral do corpus analisado, no que se refere à recorrência no uso dos pronomes, identificamos:

\section{- Maior recorrência (predomínio) no uso do pronome relativo que.}

Lembremo-nos das palavras de Bastos (2002) ao dizer que não é nova a constatação de que o usuário recorre às estratégias de estruturação das relativas, contrariando a norma padrão: via de regra generaliza o que como um relativo universal.

- Poucos/raros os casos de uso dos pronomes onde / em que / qual / quem (e suas variações). 
A seguir, temos um exemplo da adequada utilização do pronome relativo que (em que):

(6) "Na situação em que se encontra a segurança pública no Brasil.

- Uso do pronome relativo cujo (e suas variações) inexistente.

Ressaltamos que em nenhuma das 20 (vinte) redações analisadas foi encontrado o uso do pronome relativo cujo, corroborando assim os apontamentos de Bagno (2011) quando discute o processo de extinção dos pronomes relativos em seu emprego padronizado. O desaparecimento do cujo no PB (diz-se Português Brasileiro) torna estruturas como O livro de história cuja capa está rasgada... cada vez mais raras, mesmo no padrão culto (BECHARA, 2012).

Em relação à recorrência no uso das orações adjetivas, temos:

\section{- Predomínio no uso das adjetivas restritivas:}

(7) "os grupos criminosos que atuam no Brasil devem ser combatidos"

- Raros casos de adjetivas livres (CASTILHO, 20126):

(8) “[...] a única certeza que temos é que esse mundo só acaba para quem morre

- Utilização da oração adjetiva cortadora:

(10) "pessoas se prendem nas suas próprias casas, mesmo em ambientes que [em que] não haja nenhum risco para sua vida."

Como já apontado, a relativa cortadora recebe esse nome porque a preposição que rege o verbo é cortada, ou seja, é apagada na segunda oração. Observemos que o pronome relativo que, nessa construção, não foi precedido pela preposição $\mathrm{em}$. $\mathrm{O}$ verbo haja rege a preposição $\mathrm{em}$, motivo pelo qual a ausência da preposição no exemplo é considerada um corte, uma omissão de algo que deveria aparecer no sintagma.

As estratégias de relativização copiadora e, principalmente, a cortadora já se tornaram regras de gramática do $\mathrm{PB}$, o que significa que é impossível fazê-las desaparecer. A grande maioria dos falantes do PB, incluídos aí os mais letrados e até mesmo os professores de língua

\footnotetext{
${ }^{6}$ Castilho (2012) discorre sobre o complicado problema de estruturas nas quais se figura o pronome relativo quem. Explicitado o antecedente de quem [aquele 0], pode-se argumentar que essas sentenças estão encaixadas (são adjetivas/relativas) num sintagma nominal de núcleo elíptico.
} 
materna, não detecta nada de 'errado' nas construções relativas não normatizadas. (BAGNO, 2011, p. 910).

Com base nos aspectos de referenciação, coesão e sequenciação, encontramos:

\section{- Problemas na utilização do pronome adequado}

(11) Entretanto, o governo se mobiliza para por fim nessa onda de violência, onde [violência, da qual] a sociedade é refém do medo. A repreensão das autoridades tende a ser mais energética, onde se concentrará nas causas e não nas consequências que a criminalidade traz.

Muitas vezes, o uso excessivo/repetitivo de um mesmo conectivo - neste caso, onde - compromete a interação comunicativa, apresentando problemas de referenciação, coesão e sequenciação. Castilho (2012) comenta sobre a opção do pronome relativo onde em substituição ao pronome relativo preposicionado, ressaltando que esse pronome relativo apresenta a mesma chance de ocorrência quando o antecedente representa a noção de lugar ou tempo.

Como sabemos os estudantes ao produzir suas redações para os mais diversos fins, dentre eles o ENEM, conseguirem um efetivo emprego de elementos coesivos, terão textos bem articulados e com garantias de uma plena continuidade, recebendo assim boas avaliações no tocante a competência 04 - conhecimento dos mecanismos linguísticos necessários à construção da argumentação. Porém, que notas/avaliações esperar de alunos - pelo menos nessa competência - que apresentam, desde limitações no reconhecimento e aplicação dos pronomes relativos e suas variações - por assim dizer, das orações adjetivas/relativas - como já apontado e presentes na maioria das 20 (vinte) redações analisadas, até problemas de estruturação - repetição, uso inadequado de concectores, por exemplo, uma vez que, tais problemas influenciam diretamente na boa articulação entre as ideias (argumentos) - coesão, sequenciação e textualidade da redação.

\section{Considerações finais}

Propusemo-nos a analisar, neste trabalho, a recorrência dos pronomes relativos e orações adjetivas em produções textuais de candidatos ao ENEM submetidas à avaliação do portal UOL Educação, além de perceber quais conectores e tipos de orações adjetivas são os mais utilizados, levantando hipóteses de caráter didático a respeito dos resultados 
encontrados, o que faremos agora. Dessa forma, podemos organizar nossas considerações finais em três linhas de frente.

No que diz respeito aos resultados quantitativos dos dados, comprovamos dois postulados teóricos acerca do tema. O primeiro sobre o uso quase que genérico do pronome relativo que, segundo Castilho (2012), em detrimento dos demais pronomes que, normalmente, são pouco empregados e, quando o são, são usados de modo inadequado. Nessa mesma linha, chegamos à segunda conclusão: o pronome cujo caiu em desuso no Português Brasileiro, conforme apontou Bagno (2011). Mesmo nas redações avaliadas com as notas mais altas não foi encontrado, entre as 20 (vinte) analisadas, nenhuma ocorrência do cujo e suas variações. Mesmo que não sendo utilizado habitualmente em contexto de fala, era algo esperado dada a formalidade da tipologia textual requerida: texto dissertativo argumentativo.

Outra frente de discussão se abriu quando comparamos os resultados da pesquisa com estudo de Decat (2004) sobre as orações relativas apositivas como estratégias profícuas para o desenvolvimento da focalização e, sobretudo, da argumentação em uma produção textual, exercendo função textual-discursiva de avaliação e retomada do dito. Os resultados mostraram que os alunos recorreram em sua maioria ao uso de orações adjetivas restritivas por razões que, para nós, ainda não são muito claras.

Por fim, a última frente diz respeito ao ensino de orações adjetivas. Essa frente se consolida como sendo uma combinação das duas anteriores somada a um tópico crítico. A pobreza linguística encontrada nas redações analisadas, desde o uso maciço do pronome que ao uso das orações adjetivas restritivas, percebemos que os alunos não estão sendo expostos à diversidade, à riqueza da língua. É possível ver, então, a predominância do método tradicional estrutural no ensino de Língua Portuguesa. A visão funcionalista da língua parece enfrentar grandes e sólidas barreiras para entrar nas salas de aula do país já que conteúdos como as estratégias de relativização parecem não ter lugar nesses espaços. Certamente, corrobora ainda mais com este quadro crítico, a grande defasagem no histórico de leitura desses alunos (o que não é apenas responsabilidade da escola, mas certamente ela deveria impulsionar) que já é cultural, mas é negativa para o desenvolvimento até mesmo cidadão dos alunos.

\section{Referências}


BAGNO, M. Gramática pedagógica do português brasileiro. São Paulo: Parábola Editorial, 2011.

BASTOS, W. A. Ordem de constituintes em relativas. Estudos lingüísticos XXXI, São Paulo:v.31, 2002.

BECHARA, E. Moderna gramática portuguesa. 37.ed.rev.,ampl. e atual. Conforme o novo Acordo Ortográfico. Rio de Janeiro: Nova Fronteira, 2009.

BRASIL. Ministério da Educação. ENEM - Exame Nacional do Ensino Médio. A Redação no ENEM 2013 - Guia do Participante. / Ministério da Educação. Instituto Nacional de Estudos e Pesquisas Educacionais Anísio Teixeira (Inep). Diretoria de Avaliação da Educação Básica (Daeb). - Brasília - DF: MEC, 2013.

CASTILHO, A. Nova gramática do português brasileiro. São Paulo: Contexto, 2012.

CUNHA, C. \& C., Lindley. Nova Gramatica do Português Contemporâneo. Rio de Janeiro: Nova Fronteira, 3a ed..2001.

DECAT, M. B. N. Orações relativas apositivas: SNs 'soltos' como estratégia de focalização e argumentação. Veredas Revista de Estudos Linguísticos. Vol. 8, nº 1 e 2. Juiz de Fora: Minas Gerais, 2004.

GERALDI, J. W. (org.). O texto na sala de aula. 4a . ed. São Paulo: Ática, 2002.

NEVES, M. H. de M. Que gramática ensinar na escola? Norma e uso na Língua Portuguesa. São Paulo: Contexto, 2003.

PERINI, M. A. Gramática Descritiva do Português. 4ª edição. São Paulo: Ática, 2003.

PORTAL UOL - Educação. Banco de Redações. Disponível em <http://educacao.uol.com.br/bancoderedacoes/>. Acesso em 12/03/2014.

PORTAL UOL - Educação. Temas. Disponível em

<http://educacao.uol.com.br/bancoderedacoes/temas.jhtm>. Acesso em 12/03/2014.

Recebido em 29 de setembro de 2014 Aceito para publicação em 19 de dezembro de 2014 